УДК 372.881.111.1

DOI: $10.18384 / 2310-7219-2015-3-32-37$

\author{
Беленкова Н.М., Крузе И.И. \\ Российский университет дружбы народов (г. Москва)

\section{О РЕЗУЛЬТАТАХ ЭКСПЕРИМЕНТА ПО ПОДГОТОВКЕ СУДЕБНЫХ ПЕРЕВОДЧИКОВ В НЕЛИНГВИСТИЧЕСКОМ ВУЗЕ}

Аннотация. Подготовка переводчиков для специальных областей в вузе включает в себя, в первую очередь, развитие у студентов иноязычных умений и компетенций. Поскольку специальный перевод осуществляется в таких областях, как медицина, юриспруденция, образование и т.д., будущие переводчики должны знать и изучать специфические особенности той области знаний, в которой они предполагают осуществлять перевод. Данная работа особое внимание уделяет необходимости реализовать на практике предметно-лингвистический интегрированный подход к обучению судебных переводчиков в нелингвистическом вузе, представляет презентацию и выводы экспериментального обучения, которое проходило на кафедре иностранных языков юридического института Российского университета дружбы народов.

Ключевые слова: интегрированное обучение, лингво-предметное обучение, перевод в юридической сфрере, развитие умений устного переводчика, экспериментальное обучение.

\author{
N. Belenkova, I. Kruse \\ People's Friendship University of Russia, Moscow
}

\title{
EXPERIMENTAL FINDINGS OF COURT INTERPRETERS' TRAINING AT NON-LINGUISTIC HIGHER EDUCATION INSTITUTION
}

Abstract. Training interpreters specializing in specific translation at a university implies the improvement of foreign language skills and competencies. Since the interpreting can be done in such spheres as: medicine, law, education, etc., the interpreters-to-be should know and learn special features of the sphere of knowledge they are assumed to interpret. This paper focuses on the importance of the content and language integrated approach in training court interpreters at a non-linguistic higher education institution. The results of the experiment training held at the Foreign Languages Department of Law Institute of the Peoples' Friendship University of Russia are given together with the experiment conclusions.

Key words: integrated training, content and language teaching, translation in jurisprudence, interpreter's skills development, experimental training.

Всесторонне международное сотрудничество; образовательная, трудовая и академическая мобильность населения в Европейском Союзе и

(С Беленкова Н.М., Крузе И.И., 2015. во всем мире способствует многосторонним отношениям в различных социальных сферах поликультурной среды и более высокому спросу на переводчиков в различных социальных 
сферах. В связи с этим многие высшие учебные заведения открыли программы по подготовке переводчиков в той или иной области. Университеты нелингвистического профиля, осуществляющие подготовку специалистов в таких областях, как медицина, образование, юриспруденция, внедряют программы дополнительного образования в соответствующей сфере деятельности. Большинство переводчиков в сфере юриспруденции получают профессиональную подготовку в юридических институтах или на факультетах, где обучение иностранному языку интегрировано в процесс изучения различных аспектов юриспруденции, кодексов, статей законов, юридической документации и т.д., связанных с данной профессиональной средой.

При таком интегративном подходе иностранный язык выступает, с одной стороны, как инструмент для приобретения дополнительных знаний о предмете, с другой - информация, полученная при изучении определенных тем, оказывает влияние на содержание курса изучаемого иностранного языка. Интегрированное изучение специальных предметов и иностранного языка формирует основу лингво-предметного обучения, что способствует дальнейшему развитию профессиональных навыков и компетенций специалистов, расширению знаний обучаемых в определённой сфере профессиональной деятельности [5].

Использование интегрированного лингво-предметного обучения для подготовки переводчиков в сфере юриспруденции имеет важное значение. Юридический перевод считается одним из самых сложных. Очевидно, что переводчик должен быть в курсе современного законодательства, а также знать и уметь использовать специальную лексику и терминологию на иностранном языке в определённом юридическом контексте (например, уголовное, гражданское, административное право и т.п.). Юридический перевод всегда содержит ряд трудностей, так как невозможно осуществлять какой-либо перевод без глубоких юридических знаний, с одной стороны, и знания специальных терминов, фраз и словосочетаний юридического иностранного языка - с другой.

Например, слово nuisance в международном стандарте английского языка означает 'неудобство, раздражение, проблемы', но в юридическом английском языке оно означает, 'вред или источник опасности, нарушение общественного порядка (e.g. public nuisance)'. Слово consideration в международном стандарте английского языка синонимично словам 'мысль, размышление, внимание', а в правовом контексте оно используется в значении 'ближайшая цель, которую преследуют стороны договора; встречная компенсация' и т.п. [6]. Понятие «судебный перевод» связано не только с переводом в зале суда, оно значительно шире и отражает деятельность переводчика в любой правовой сфере, например, в полицейском участке, в органах следствия, в службе иммиграции [10].

В немецком языке также можно найти подобные примеры: так, слово der Bulle имеет значение 'бык' (das Rind), а в юридической терминологии это - полицейский (der Polizist). Слово das Gericht, с одной стороны, означает ‘блюдо' (die Mahlzeit), а с другой - это 'суд' (das Rechtswesen). 
Тем не менее глубокое знание соответствующей темы и терминологии недостаточно для успешного перевода, не всегда можно легко подобрать эквивалент какому-либо термину или устойчивому выражению. Многие проблемы, с которыми сталкивается судебный переводчик, связаны с тем, что в языке, на который осуществляется перевод, нет структур или понятий оригинального языка и которые нужно отразить в переводе. Кроме того, поскольку текст и высказывание зависят от культурных особенностей и менталитета народа, а также национальной правовой системы, смысл текста на языке оригинала часто может не соответствовать понятиям на переводимом языке. Очень часто национальные законодательные системы не совпадают, и те же аспекты могут восприниматься по-разному.

Отсутствие достаточных знаний о некоторых аспектах юридической системы США могут привести к непониманию многих вопросов. Например, limited divorce - это 'развод под наблюдением суда, когда супруги не имеют оснований для абсолютного развода' [8]. Если неопытный переводчик без соответствующих правовых знаний переведёт этот термин с английского на русский, это выражение можно понять, как развод, ограниченный по некоторым вопросам.

Сочетание The US Department of the Interior часто переводится как 'Министерство внутренних дел', но на самом деле эти структуры нельзя сравнивать, так как the US Department of the Interior отвечает за охрану природных ресурсов, культурного наследия и т.д. [11], в то время как Министерство внутренних дел Российской Федера- ции является федеральным органом исполнительной власти, ответственным за разработку и реализацию государственной политики и за нормативно-правовое регулирование в сфере внутренних дел. В Германии слово das Unterlassen в уголовном праве означает 'бездействие' (Nichtstun), а в гражданском - 'воздержание от действия' (Nichtvorname einer Handglung).

Очевидно, эти примеры показывают, что юридические знания является обязательными для судебного переводчика. Однако противники этой точки зрения настаивают на том, что переводчик - это достаточно распространённая и универсальная профессия, которая подразумевает знание двух языков, но не знаний в области права на уровне эксперта. Судебный переводчик, в первую очередь, лингвист, а не юрист. Специальная подготовка переводчика должна включать в себя краткий курс права, но не глубокое изучение юриспруденции [7]. Кроме того, поскольку процесс перевода в суде включает в себя несколько участников речевой коммуникации с определённым уровнем развития логики, интуиции и здравого смысла, это помогает избежать возможных (и иногда даже неизбежных) ошибок переводчика.

Исследование, проведённое на кафедре иностранных языков юридического институт РУДН, включало педагогический эксперимент, в котором участвовали студенты, обучающиеся по программе дополнительного профессионального образования по подготовке переводчиков в сфере юриспруденции. Были использованы пред- и пост- экспериментальное тестирование для оценки умений, сформированных у студентов. 
Ранее предметом исследования являлся процесс подготовки переводчиков в сфере юриспруденции среди студентов, изучающих английский язык [3; 4]. В данном исследовании приняли участие студенты, изучающие немецкий язык.

Общее количество студентов, принявших участие в обучающем эксперименте, составило 60 человек, целью обучения явилось совершенствование лингвистических навыков и компетенций устного переводчика. Для этой цели был использован учебно-методический комплекс: Dengler S., Rusch P., Schmitz H., Sieber T. Netzwerk A2, KlettLangenscheidt, 2013.

Кроме вышеуказанного учебного пособия, были использованы учебные материалы с информацией о различных аспектах права и законодательства. В первую очередь, интернетсайты, представляющие подробную информацию о правовых системах Германии и Австрии, стали источником дополнительного материала аудиторных и внеаудиторных занятий, а также видео материалы на сайте Das Erste [12].

В начале эксперимента были протестированы умения студентов в устном переводе. Все студенты должны были перевести устно определённое количество слов и фраз с немецкого на русский язык и с русского на немецкий (Rückübersetzung). В тест входили слова и фразы из коммуникативного, общеразговорного немецкого языка (Kommunikatives Deutsch).

Принимая во внимание, что средняя скорость речи в русском языке равна 120 слов в минуту [1], мы предположили, что первоначальное испытание должно продолжаться в течение
5 минут и состоять из четырёх частей. Студент должен перевести 20 слов с немецкого языка на русский и 10 фраз, состоящих из 5 или 7 слов с немецкого языка на русский, далее 25 слов с русского языка на немецкий язык и 5 фраз с русского языка на немецкий.

Перед выполнением теста студенты прослушивают краткую инструкцию о цели теста и порядке его выполнения. Каждая часть теста длится около минуты. Разница в количестве слов и фраз, предназначенных для перевода, объясняется трудностями, вызванными пониманием иностранного слова на слух и проблемами, связанными с межъязыковым декодированием. Тест и ответы студентов были записаны на аудиофайле в электронном формате, затем записанные файлы с результатами тестирования были проанализированы (об использовании Веб технологий для подготовки переводчиков см. [2]).

Результаты испытаний показали, что около 50 \% студентов сделали по 2-3 ошибки при переводе с немецкого языка на русский, около 3-4 слов или фраз оказались незнакомыми. При переводе с русского на немецкий, студенты сделали примерно 3-4 ошибки и испытывали затруднения при переводе 4-5 слов и в среднем 2 фраз.

После проведения тестирования группы продолжили работать с УМК "Netzwerk A2". Согласно учебному плану, при работе с этим УМК студенты впервые затрагивают профессионально ориентированную тематику при изучении темы 5 "Was Machen Sie beruflich?", т.е. приблизительно через 3 месяца после начала учебного процесса и проведения первого теста. В это время студенты начинают изучать 
лексику по специальности «Юриспруденция» и развивать свои навыки и умения устного переводчика, постоянно упражняясь в устном переводе отдельных слов, словосочетаний и предложений с немецкого языка на русский и с русского на немецкий. Для этих целей часто используются следующие задания: "Wählen Sie die richtige Variante aus drei vorgeschlagenen" ('Выберите правильный вариант из трех предложенных'); “Wählen Sie die passende wörtliche Übersetzung" ('Выберите правильный перевод'). Задание "Vollenden Sie die Sätze" ('Завершить предложение') предполагает завершение предложений, используя те слова и словосочетания, которые были изучены ранее. Все задания выполняются в устной форме, при этом улучшается вербальная память и внимание студентов, их способность межъязыкового декодирования.

Кроме того, студенты знакомятся с различными аспектами российского законодательства и законодательства Германии. Они ищут на интернет-сайтах дополнительную информацию по темам, рассматриваемым на занятиях и связанным с будущей профессией студентов, изучают различную профессиональную литературу, а также материалы из средств массовой информации. При этом студенты получают первоначальные профессиональные знания и умения. Обучаемые также могут быть вовлечены в дискуссии по профессиональным вопросам на иностранном языке.

Студенты проявляют значительный интерес к различным профессионально ориентированным заданиям на занятиях по иностранному языку. Они готовят материал и выступают с презентациями, например, "Der Gang Eines Strafverfahrens” ('Ход уголовного дела') и работают в мини-группах, изучая специальную лексику в режиме устного перевода немецкий - русский, русский - немецкий. Разработан специальный комплекс упражнений по обучению устному переводу, включающий в себя совокупность различных заданий и упражнений, выполняемых в определённой последовательности и необходимом количестве, с учётом закономерностей формирования переводческих компетенций. Задача разработки комплекса - апробация условий обеспечения максимально высокого уровня освоения профессиональной переводческой деятельности [9]. Развитие переводческих умений осуществляется на каждом занятии в течение примерно 4 минут.

К концу семестра студенты вновь были протестированы. Заключительный тест, который проводился в конце семестра, напоминал начальный тест, он включал те же составляющие, время испытания составляло 5 минут. При этом опции теста были другими: в тест были включены слова и словосочетания, связанные с юридической тематикой. Все языковые единицы теста были знакомы студентам обеих групп, студенты встречали их при чтении и воспринимали при аудировании различной профессиональной информации, активно использовали в разговорной практике, при выполнении письменных работ на занятиях по иностранному языку или во время просмотра интернет-сайтов для поиска специальной информации.

Результаты финального теста значительно отличались от результатов первичного теста: 70 \% обучаемых не 
сделали ни одной ошибки, и 30 \% обучаемых сделали несколько ошибок или не вспомнили необходимые слова или словосочетания.

Результаты исследования показали, что при изучении различных вопросов права и законодательства на иностранном языке студенты повышают свои знания специальной терминологии и общий запас слов в целом и, следовательно, сталкиваются с меньшими трудностями при декодировании высказывания с одного языка на другой. Обучение устному переводу является более эффективным и успешным, если в практике используются различные типы специальных заданий.

\section{ЛИТЕРАТУРА:}

1. Психологос [Электронный ресурс]. URL: http://www.psychologos.ru/ categories/view/psihologiya_dlya_profi (Дата обращения: 10.07.2015).

2. Титяева Г.В. Формирование профессиональной компетентности будущих лингвистов-переводчиков посредством технологий Веб 2.01 // Вестник Московского государственного областного университета. Серия: Педагогика. 2012. №3. C. 147-152.

3. Atabekova A. Non-formal content and language integrated learning: towards student's assessment methodology, 9th International Technology, Education and Development Conference, 2-4 March, 2015, Madrid, Spain. [Электронный ресурс]. URL http://library.iated.org/view/ATABEKOVA2015NON (дата обращения: 13.07.2015).

4. Belenkova N. CLIL Approach and Teachning LSP - Two Ways to the Same Goal?
Proceedings of ICERI2014 Conference, 17th-19th November 2014, Seville, Spain, libreriauniversita-ria.it edizioni, pp 30763079, 2014.

5. Drafting a New Strategy for CLIL in Europe. [Электронный ресурc]. URL http:// www.britishcouncil.org/sites/britishcouncil.uk2/files/clil_recommendations_august_14_pdf.pdf (дата обращения: 13.07.2015).

6. Gooch G., Williams M., A Dictionary of Law Enforcement (Oxford Paperback Reference). Oxford University Press, 2009, $432 \mathrm{p}$.

7. Guozheng W. Traduction juridique. Une lacune? tonnante: aucune connaissance juridique n'est requise des interpr? tes judiciaires. [Электронный ресурс]. URL https://ssl.editionsthemis.com/uploaded/ revue/article/rjtvol37num3/07_traduction.pdf (дата обращения: 13.07.2015).

8. Legal Definitions \& Legal Terms 'L' List // http://definitions.uslegal.com/l/ (дата обращения: 13.07.2015).

9. Małgorzewicz A., Entwicklung der translatorischen Kompetenz im Rahmen des Postgradualen Studiums für Sprachmittler an der Universität Wrocław [Электронный ресурc]. URL http:// www.fask.uni-mainz.de/user/hagemann/ publ/malgorzewicz.pdf june _02_pdf.pdf (дата обращения: 13.07.2015).

10. Shuttleworth M., Cowie M. Dictionary of Translation Studies. St. Jerome Publishing, 1997, $233 \mathrm{p}$.

11. US Department of the Interior [Электронный pecypc]. URL: http://www.doi.gov/index.cfm (Дата обращения: 10.07.2015).

12. Das Erste [Электронный pecypc]. URL: http:// www.daserste.de/ratgeber/ recht_default.asp (Дата обращения: 10.07.2015). 